\title{
"JATIDIRI PASUNDAN" SEBAGAI BRANDING BANDUNG TV DALAM MENGHADAPI TANTANGAN ISI SIARAN DI ERA DIGITALISASI
}

\author{
Ahmad Taufiq Maulana Ramdan', Yanti Setianti², Aat Ruchiat Nugraha² \\ ${ }^{1}$ Karyawan Kontrak Bandung TV \\ ${ }^{2}$ Universitas Padjadjaran
}

\begin{abstract}
ABSTRAK
Keberadaan televisi lokal menyongsong era digitalisasi akan semakin tertantang dengan adanya persaingan untuk mendapatkan perhatian publik yang semakin kritis dan tersegmentasikan dengan jelas. Persaingan diantara industri penyiaran lokal dapat diatasi melalui tayangan isi siaran yang mengandung nilai-nilai budaya sebagai keunggulan sebuah televisi lokal di suatu daerah. Tuntutan isi siaran pada televisi lokal harus harus mengimbangi terhadap perkembangan budaya modern dan teknologi informasi yang semakin "bebas" memasuki ruang pribadi dan ruang publik secara berkesinambungan. Disisi lain, televisi sebagai media komunikasi massa yang cukup ampuh dalam menyampaikan pesanpesan terhadap publik telah merubah pemikiran dan budaya bangsa secara bertahap. Hal inilah yang terdapat pada isi siaran televisi lokal Bandung TV yang masih tetap mempertahankan isi siaran dengan konsep-konsep budaya lokal Kesundaan sebagai identitas Branding keberadaan televisi lokal di era persaingan siaran analog dan digital yang semakin kompetitif. Tujuan penelitian ini adalah untuk mengetahui dan menjelaskan bagaimana Bandung TV membangun branding "Jatidiri Pasundan" melalui program tayangan advertorial gelaran event 1001 produk wirausaha baru Jawa Barat 2016. Metode penelitian yang digunakan adalah deskriptif dengan pendekatankualitatif. Teknik pengumpulan data yang digunakan melalui observasi, wawancara, dan studi kepustakaan. Hasil dari penelitian menunjukkan bahwa konsep tayangan yang menunjang branding "Jatidiri Pasundan" disiarkan dengan penggunaan bahasa Sunda lomamengenai isi tayanganevent Gelar 1001 Produk Wirausaha Baru Jawa Barat 2016. Simpulan dari penelitian ini bahwa Bandung TV telah berhasil menanamkan sebagian dari nilai-nilai "Jatidiri Pasundan" dalam tayangan event Gelar 1001 Produk Wirausaha Baru Jawa Barat 2016.
\end{abstract}

Kata-kata Kunci: Siaran Televisi, Branding, Televisi Lokal

\section{"PASUNDAN IDENTITY” AS BANDUNG TV BRAND IN FACING THE CHALLENGES OF BROADCAST CONTENTS IN THE DIGITALIZATION ERA}

\begin{abstract}
The existence of local television welcome sthe era of digitalization will be increasingly challenged by their competition for public attention which is increasingly critical and clearly segemented. Competition among local broadcasting industry can be addressed through the broadcast contents which contain cultural values as a local television excellence in an area. The demands of broadcast content on local television must keep pace with the development of modern culture and increasingly "free" information technology entering private space and public space on an ongoing basis. On the other hand, television as a mass communication media has enough power to change gradually the culture and the way the nation think. This is actually the basic content in Bandung TV, it retains broadcast that contains concepts of local culture 'sundanese' as the identity Branding local television in the era of analog and digital broadcast that is increasingly competitive. The purpose of this study was to determine and explain how to build a brand of "Identity Pasundan" in Bandung TV through the mat program advertorial event show 1001 new entrepreneurs products in West Java in 2016. The method used is descriptive qualitative approach. Data collection techniques used through observation, interview, and literature study. Results from the study showed that the concept of branding impressions that support the "Identity Pasundan" broadcast with the use of Sundanese Loma impression regarding the contents of event Held Products 1001 New Entrepreneurs of West Java2016. The conclusion showed that Bandung TV had managed to instill some of the values of "Identity Pasundan" in-view event Held Products 1001 New Entrepreneurs of West Java in 2016.
\end{abstract}

Keyword: Television Broadcast, Branding, Local Television

Korespondensi: Aat Ruchiat Nugraha, S.Sos., M.Si. Universitas Padjadjaran. Jl. Raya Bandung-Sumedang Km. 21 Sumedang 45363. Email: aatruchiat.nugraha@gmail.com

Submitted: November $3^{\text {rd }}$, 2016, Revision: January $3^{\text {rd }}$, 2017, Accepted: March $3^{\text {rd }}, 2017$

ISSN: 2548-687X (cetak), ISSN: 2549-0087 (online)

http://jurnal.unpad.ac.id/protvf 


\section{PENDAHULUAN}

Televisi lokal memiliki positioning yang kuat sebagai media lokal disuatu daerah. Keberadaan televisi lokal sebagai lembaga penyiaran daerah, dituntut untuk dapat menerjemahkan dan menyukseskan amanah dari otonomi daerah dengan mengembangkan konten-konten positif berbasis kearifan lokal, yang dikemas dalam berbagai penyajian berupa berita, musik, hiburan, program kesenian, kebudayaan, hingga potensi ekonomi lokal suatu daerah. Televisi lokal juga memunculkan berbagai permasalah yang ada untuk kemudian disampaikan dalam bentuk berita, opini maupun penyajian lainnya, setiap lembaga penyiaran memiliki tanggung jawab dalam menjaga nilai moral, tata susila, budaya, kepribadian dan menjaga integrasi nasional serta kesatuan bangsa.

Bandung TV merupakan salah satu media televisi lokal yang berada di kota Bandung, hadir sebagai perwujudan kreativitas seni budaya masyarakat Sunda. Bandung TV juga merupakan televisi lokal pertama di Bandung dan di Jawa Barat yang program acaranya menayangkan aspek-aspek kehidupan masyarakat dan seni budaya Sunda. Pendekatan seni budaya sangat tepat mengingat seni budaya merupakan poros kehidupan yang menggerakan dimensi sosial dan ekonomi masyarakat, khususnya masyarakat Sunda di kota Bandung.

Keberadaan Bandung TV didukung oleh amanat UU No 32/2002, Pasal 6 ayat (2) yang
TANTANGAN ISI SIARAN DI ERA DIGITALISASI

menyebutkan bahwa dalam sistem penyiaran nasional terdapat lembaga penyiaran dan pola jaringan yang adil dan terpadu yang dikembangkan dengan membentuk stasiun jaringan dan stasiun lokal. Selanjutnya, menurut PP No 50 Tahun 2005, penyiaran diselenggarakan dalam suatu sistem penyiaran yang memiliki prinsip dasar keberagaman kepemilikan dan keberagaman program siaran dengan pola jaringan yang adil dan terpadu dalam pemberdayaan masyarakat daerah.

Berdasarkan wawancara pra riset dengan Herdi ST.,M.Sn sebagai program manager Bandung TV, disampaikan bahwa kehadiran Bandung TV merupakan pelopor televisi lokal di Jawa Barat sekaligus sebagai ikon media dengan latar belakang budaya Sunda. Kehadiran Bandung TV dengan brand "Jatidiri Pasundan" memperjelas bahwa Bandung TV merupakan wadah untuk mengekspresikan informasi, budaya, sosial, ekonomi dan pariwisata Jawa Barat. ${ }^{1}$

Brand "Jatidiri Pasundan" memperkuat positioning Bandung TV sebagai media lokal, meskipun sejak berdiri Bandung TV hingga saat ini telah tiga kali berganti logo namun brand "Jatidiri Pasundan" tidak pernah berubah. Target audience, formula dan komposisi serta metode penyiaran tetap fokus pada program acara berbasis budaya lokal. Bandung TV merupakan satu-satunya TV lokal di Jawa Barat yang masih sepenuhnya fokus pada budaya lokal.

\footnotetext{
${ }^{1}$ Wawancara pra-riset dengan Kang Herdi tanggal 11 Maret 2016
} 
ProTVF, Volume 1, Nomor, 1, Maret 2017, Hal. 31-46

Menurut Bapak Herdi, sikap fokus terhadap budaya Sunda dibuktikan dengan penamaan acara-acara di Bandung TV yang "nyundaan" misalnya Bentang Parahyangan, Mandalawangi, Geulis dan semacamnya.Dalam setiap program acara Bandung TV melakukan kegiatan branding agar terbentuk persepsi yang diharapkan dalam benak pemirsa.Branding menurut Aaker (2015:26)) adalah salah satu faktor kesuksesan dalam sebuah bisnis. Tentu semua bisnis menginginkan mereknya bisa dikenal oleh masyarakat luas dan dapat diterima dengan baik oleh mereka. Karena merek adalah hal pertama yang akan keluar dibenak konsumen ketika ingin membeli suatu produk.

Keterbatasan investasi dan lemahnya daya saing dengan televisi nasional menjadi kendala tersendiri sekaligus tantangan bagi televisi lokal untuk bersaing dengan televisi nasional, hal ini mengakibatkan Bandung TV meskipun kesulitan untuk mengembangkan dirinya.Namun demikian, Bandung TV terus bekreatifitas. Popularitas televisi lokal ditengah masyarakat saat ini kalah jauh dengan televisi nasional, hal ini berakibat pada minimnya sponsor yang masuk, sementara perolehan iklan merupakan income utama bagi keberlangsungan media televisi.

Dilema keberadaan televisi lokal tidak menyurutkan semangat Bandung TV dalam meningkatkan perannya membentuk karakter dan cara pandang pemirsa (penonton)nya terhadap pengembangan budaya Sunda, misalnya seseorang yang kurang peduli terhadap budaya Sunda diharapkan setelah menontonprogram acara Bandung TV menjadi tertarik dan peduli terhadap budaya Sunda. Kenyataan ini merupakan suatu tantangan bagi Bandung TV untuk terus berusaha mengkomunikasikan brand"Jatidiri Pasundan".Menurut Aaker(2015:26), brand adalah aset yang bernilai strategis. Penegasan ini mengubah segala sesuatu, tetapi perlu dikomunikasikan dalam cara yang meyakinkan demi memotivasi satu organisasi untuk berinfestasi dalam brand-building dan dalam melindungi aset-aset brand.

Berbagai upaya dilakukan Bandung TV dalam memantapkan branding "Jatidiri Pasundan" melalui pengemasan program acara di televisi, pengemasan media sosial, serta keterlibatan dalam berbagai event, baik yang diselenggarakan oleh Bandung TV maupun berkerjasama dengan lembaga atau organisasi lain, sebagai wujud nyata menghadapai era persaingan siaran digital. Berbagai acara dikemas dan ditayangkan sesuai branding Jatidiri Pasundan,mulai dari konsep-konsep acara, penamaan acara, musik, bahasa yang digunakan, kostum para pengisi acara dan sebagainya.

Dalam wawancara dengan Kang Arya, salah seorang produser program acara acara di Bandung TV disampaikan bahwa melakukan branding "Jatidiri Pasundan" dalam setiap program acara pada saat ini menjadi tidak mudah. $^{2}$ Artinya pada satu sisi mereka harus mengurangi program acara-program acara budaya Sunda, dan menambah program acara

\footnotetext{
${ }^{2}$ Wawancara pre-riset dengan Kang Arya tanggal 11 Maret 2016
} 
TANTANGAN ISI SIARAN DI ERA DIGITALISASI

dengan muatan "modern" sesuai anjuran, pada sisi lain mereka harus tetap mengusung idealisme TV lokal dalam mengangkat budaya daerah khusunya melakukan branding "Jatidiri Pasundan".

Sementara itu, wawancara yang dilakukan dengan pembawa acara atau host pada program acara Bandung TV, Kang Bagus menyatakan bahwa branding Jatidiri Pasundan yang dilakukan oleh Bandung TV masih harus dibenahi lagi, terutama pada host yang bukan merupakan duta bahasa namun harus menggunakan bahasa sunda dalam program acara acaranya. ${ }^{3}$ Hal tersebut menjelaskan bahwa sejak ditetapkan "Jatidiri Pasundan" sebagai brand Bandung TV, berbagai kegiatan untuk mengkomunikasikan brand tersebut belum maksimal. Kegiatan branding secara rutin mereka lakukan melalui program acara on air maupun off air (event), namun karena keterbatasan dana dan fasilitas yang ada, Bandung TV belum dapat melakukan nya dengan maksimal.

Adanya fakta bahwasanyatelah 11 tahun Bandung TVmelakukan berbagai cara untuk mengkomunikasikan brand Jatidiri Pasundan, namun masih banyak pemirsa yang menjadi sasaran dari brand Bandung TV ini belum mengetahui bahwa Bandung TV memiliki brand "Jatidiri Pasundan".

Menerapkan strategi branding merupakan hal yang wajib bagi Bandung TV sebagai TV lokal,pergantian kepala pemerintahan daerah

${ }^{3}$ Wawancara pra-riset dengan Kang Bagus tanggal 15 maret 2016
Jawa Barat menjadi tantangan baru untuk Bandung TV agar menciptakan kepercayaan baru bagi pemerintahan yang baru. Komunikasi yang dilakukan dalam kegiatan branding ini bertujuan untuk dapat meningkatkan pandangan serta keyakinan stakeholder serta berusaha mengembangkan persepsi masyarakat dan memberikan pengalaman yang "berkesan" terhadap "Jatidiri Pasundan". Yang pada akhrnya, diharapkan begitu mendengar kata Bandung TV, masyarakat (pemirsa) akan langsung mempersepsi brand "Jatidiri Pasundan" dan merasakan berbagai pengalaman akan kebudayaan Sunda. Ada Bandung TV ada "Jatidiri Pasundan", ada budaya Sunda.

Merek (brand) adalah sebuah identitas yang dibuat oleh orang-orang pemasaran agar memudahkan konsumen memilih sebuah produk. Menurut Wasesa (2011:7) menjelaskan bahwa merek dapat disebut sebagai sebuah kumpulan ekuitas sebuah produk.Menurut Aaker (2015:3) menyebutkan brand adalah aset yang menggerakan strategi. Sekitar tahu 1980-an, sebuah idea dahsyat muncul, yaitu pemikiran bahwa brand adalah aset, memiliki ekuitas, dan menggerakan strategi serta performa bisnis. Konsepsi brand sebagai aset menimbulkan arus perubahan yang dramatis dan besar pengaruhnya; mengubah persepsi pemasaran dan manajemen brand, bagaimana seharusnya brand dikelola dan diukur, dan peran para eksekutif pemasaran. Lebih jauh, Aaker menjelaskan bahwa perusahaanperusahaan yang mengadopsi dan berhasil 
mengimplementasikan pandangan ini telah menyaksikan brand building beralih dari upaya taktis yang dapat didelegasikan dengan aman melalui satu tim komunikasi menjadi sebuah penggerak strategi bisnis.

Aaker (2015:4) menjelaskan penerimaan konsep "brand sebagai aset" semakin marak berkat fakta keyakinan bahwa peran utama pemasaran brand adalah untuk merangsang penjualan telah gagal dalam banyak konteks. Selain itu para eksekutif melihat bahwa aset brand itu diperlukan untuk menciptakan pertumbuhan garis atas yang telah menjadi sangat penting bagi banyak perusahaan karena program penurunan biaya telah mencapai titik dimana hal tersebut tak lagi memberikan pengaruh yang menguntungkan. Lebih jauh Aaker (2015:5) menjelaskah bahwa pandangan brand adalah aset merupakan pandangan valid yang didukung oleh data kuantitatif. Sisi validitas berasal dari kesadaran bahwa para pelanggan, khususnya dalam konteks pelayanan dan bisnis ke bisnis, sedangkan membuat keputusan pembelian dan menilai pengalaman pembisnis dalam menggunakan elemen-elemen brand yang ada diluar harga dan atribut fungsional. Dukungan kuantitatif untuk brand sebagai aset didasari oleh data hasil riset yang menunjukan bahwa brand memang memiliki nilai aset yang subtantial sehingga paradigma baru bahwa brand sebagai aset begitu menggoda para CFO dan CEO diseluruh dunia.
METODE PENELITIAN

Metode yang digunakan dlam penelitian ini adalah metode deskriptif dengan pendekatan kualitatif. Metode deskriptif menurut Rakhmat (1989:34) merupakan penelitian yang hanya memaparkan situasi atau peristiwa. Penelitian deskriptif tidak mencari atau menjelaskan hubungan, tidak menguji hipotesis atau membuat prediksi. Tujuan metode deskriptif menurut Isaac dan Michael (dalam Rakhmat, 1989:30) adalah melukiskan secara sistematis fakta atau karakteristik populasi tertentu atau bidang tertentu secara faktual dan cermat.

Objek penelitian ini peneliti memaparkan situasi atau peristiwa branding yang dilaksanakan oleh pihak Bandung TV, baik pada program-program tayangan (on air).Subjek dalam penelitian ini adalah pengelola Bandung TV dan Brand "Jatidiri Pasundan" yang dimiliki oleh Bandung TV.

Penelitian ini diawali dari adanya brand "Jatidiri Pasundan" yang dimiliki Bandung TV serta upaya-upaya yang dilakukan Bandung TV dalam membangun branding "Jatidiri Pasundan". Sebagai televisi lokal pertama di Jawa Barat Bandung TV memiliki visi untuk menjadi ikon Jawa Barat melalui brand "Jatidiri Pasundan". Adapun narasumber dalam penelitian ini adalah manajemen Bandung TV di level pimpinan puncak dan level operasional (manajer). 


\section{HASIL DAN PEMBAHASAN}

Sekilas Tentang "Jatidiri Pasundan"

\section{Bandung TV}

Jatidiri Pasundan adalah identitas yang menggambarkankarakter dan sifat masyarakat Pasundan atau disebut dengan Urang Sunda, yaitu cageur, bageur, pinter, bener dan singer. Pemimpin redaksi Bandung TV, Bapak Us menjelaskan alasan Bandung TV menetapkan brand Jatidiri Pasundan, karena menurut penilaian beliau dan tokoh-tokoh Sunda di Jawa Barat bahwa orang-orang Sunda mulai meninggalkan jatidirinya. Manusia saat ini berada dalam globalisasi yang menjadi bagian dari dunia yang lebih luas, sehingga mereka lupa terhadap jatidirinya sendiri, padahal bagaimanapun menurut Bapak Us jatidiri itu penting, karena jika tidak memiliki identitas yang jelas (jatidiri) suatu bangsa akan terombang-ambing dalam situasi yang tidak menguntungkan,globalisasi memiliki pengaruh yang besar sekali terhadap kehidupan suatu bangsa. Menurut pak Us, tidak semua yang berasal dari globalisasi itu sesuai dengan budaya serta kepribadian bangsa Indonesia khususnya masyarakat Sunda.

Bandung TV berkomitmen setidaknya membantu dan mengarahkan masyarakat Sunda agar dapat memahami tentang jatidirinya. Masyarakat Sunda harus paham benar tentang "apa itu jati diri” dan bagaimana budaya, sikap serta perilaku yang merupakan identitas orang Sunda (Pasundan). Bapak Us menjelaskan bahwa pihak pendiri dan pengelola Bandung TV pada awalnya masih
TANTANGAN ISI SIARAN DI ERA DIGITALISASI meraba-raba tentang kepastian jati diri Pasundan itu seperti apa,namun kemudian bersama-sama dengan orang-orang sunda (para tokoh Pasundan dan Seniman Jawa Barat)mulai di telusuri dan dirumuskan gambaran Jatidiri Pasundan.

Jatidiri bukan hanya budaya tetapi juga sikap hidup suatu kelompok masyarakat atau suku bangsa, yaitu bagaimana mereka menyikapi kehidupan.Singkatnya jatidiri itu tergambar pada kebudayaan dan perilaku suatu masyarakat dalam hal ini adalah masyarakat Sunda atau Pasundan.Beberapa karakter sifat kebanyakan orang Sunda digambarkan sebagai periang, optimis, ramah dan sopan.

Bandung TV melakukan brandingJatidiri Pasundan dengan tujuan untuk mengangkat kembali nilai-nilai budaya dan potensi lokal yang terdapat di Jawa Barat pada umumnya dan Bandung khususnya sebagai ibukota provinsi Jawa Barat. Logo Bandung TV terbangun dari beberapa unsur penggambaran Jatidiri Pasundan yaitu Kembang Cangkok Wijayakusumah, Kujang, serta tulisan BANDUNG merupakan manunggaling Tri Tangtu di Buana, yakni Sang Rama, Sang Resi, serta Sang Ratu, atau merupakan kesatuan hakiki dari sifat manusia linuhung yang silih asih, silih asah, serta silih asuh sebagai semangat dan falsafah orang sunda.

\section{Pengelola Bandung TV melaksanakan branding "Jatidiri Pasundan" melalui program acara televisi}

Bandung TV diyakini Kang Arya sebagai salah satu media televisi lokal yang berada di 
ProTVF, Volume 1, Nomor, 1, Maret 2017, Hal. 31-46

kota Bandung, yang hadir sebagai perwujudan kreativitas seni budaya masyarakat Sunda. Bandung TV juga merupakan televisi lokal pertama di Bandung dan di Jawa Barat yang program acaranya menayangkan aspek-aspek kehidupan masyarakat dan seni budaya Sunda. Pendekatan seni budaya sangat tepat mengingat seni budaya merupakan poros kehidupan yang menggerakan dimensi sosial dan ekonomi masyarakat, khususnya masyarakat Sunda di kota Bandung.Menurut Kang Arya, sebagai salah satu Televisi lokal bandung TV memiliki positioning yang kuat sebagai media lokal disuatu daerah. Karena televisi lokal memuat content lokal berupa berita, musik, hiburan, program kesenian, kebudayaan, hingga potensi ekonomi lokal suatu daerah. Televisi lokal juga mengemas penyajiannya dengan mengedepankan kearifan lokal yang mencakup permasalahan daerah, baik itu dari isu yang dibawa maupun dari bahasa yang digunakan.

Kehadiran Bandung TV sebagai media lokal memberi warna baru dalam dunia penyiaran tanah air karena selama ini kearifan lokal kurang optimal diang t dalam wujud audio vidual. Masyarakat lokal menaruh harapan terhadap televisi lokal, kehadiran televisi lokal diharapkan dapat memberi alternatif tontonan dan dapat mengakomodasi khazanah lokal yang saat ini kurang tertampung dalam program acara televisi.

Program acara yang bermaterikan sosial, budaya, pariwisata, ekonomi, dan unsur kedaerahan menjadi suatu kebutuhan bagi seluruh lapisan masyarakat dalam upaya optimalisasi pembangunan daerah, sehingga kehadiran televisi lokal dapat menjadi solusi penting.

Bandung TV pada awal pendiriannya masih belum memiliki brand "Jatidiri Pasundan", hal ini sesuai yang di ceritakan oleh Kang Arya sebagai berikut:

"....Branding atau motto "Jatidiri Pasundan" itu dibuat oleh komisaris ya.. ketika kita angkatan pertama pelatihan disana setiap orang yang ikut pelatihan bikin motto untuk Bandung TV, jadi bikin polling lah, setiap orang memberikan motto masing-masing tapi akhirnya yang diambil ya.. itu "Jatidiri Pasundan", cuman kesini-kesini "Jatidiri Pasundan" pas kita mau ke Bandung kita lebih mengangkat program-program budaya..."

Dalam perkembangannya Bandung TV melalui banyak perubahan dan perkembangan terhadap program acara yang dimilikinya, namun Bandung TV tetap mengedepankan brand "Jatidiri Pasundan". Bandung TV mengedepankan program acara budaya yang merupakan inti dari "Jatidiri Pasundan" serta identitas dari Bandung TV. Branding Jatidiri Pasundan menjadi misi yang harus dijalankan oleh pengelola program acara Bandung TV. Hal ini di kemukakan oleh Kang Arya sebagai Produser Bandung TV bahwa:

“...Bandung TV sendiri programnya lebih ke multisegmen sih tidak program budaya semua...cuman karena awal-awal kita lebih banyak mengangkat program budaya dan program budaya yang masuk disitu terutama program midangnya....."5

\footnotetext{
${ }^{4}$ Wawancara dengan Kang Arya pada Tanggal 23 Juni 2016

${ }^{5}$ Wawancara dengan Kang Arya pada Tanggal 23 Juni 2016
} 
TANTANGAN ISI SIARAN DI ERA DIGITALISASI

Kang Arya menjelaskan bahwa sejak awal Bandung TV merupakan tv lokal yang memang mengangkat tentang budaya lokal tanah Pasundan, namun belum memiliki brand “Jatidiri Pasundan". Dalam pelaksanaan program acaranya Bandung TV melibatkan tim kerja. Hal ini seperti yang di jelaskan oleh Kang Arya sebagai berikut:

"...kalau untuk tayangan sendiri kan disini kita dibentuk ada susunannya, ada manager programnya, ada produsernya, ada tim trafiknya juga, jadi ketika di produser mengajukan tayangan atau program kita mengonsep dulu sebelum program itu tayang, apakah layak program itu tayang di Bandung TV atau tidaknya,, seperti itu sih..."

Dalam pembuatan program acaranya Bandung TV melibatkan banyak orang yang terbagi dalam grup-grup kecil agar lebih memfokuskan terhadap program dan tema acara yang akan di jalankan atau ditayangkan. Selain itu dengan pembentukan grup-grup yang telah terfokus akan lebih memudahkan untuk mengontrol setiap program acara.Kang Arya menjelaskan bahwa hampir setiapprogram acara Bandung TV selalu dimasukan "Jatidiri Pasundan”. Hal ini dijelaskan oleh Kang Arya sebagai berikut:

"Mengangkat lebih ke "Jatidiri Pasundan"nya ketika program-program budaya masuk ada di Bandung TV gitu,,,, terutama ada program-program tayangan tarian, terus tayangan mengangkat dialog-dialog sunda kaya dulu kan ada Golempang, seterusnya ada

${ }^{6}$ Wawancara dengan Kang Arya pada Tanggal 23 Juni 2016
Midangnya, ada Mandalawanginya juga yang mengangkat sejarah kebudayaan sunda juga, jadi tidak hanya dari segi sipresenter harus memakai pakaian budaya,, enggak juga sih.... Tapi si konsep dan programnya itu yang mengangkat kebudayaan yang menciri khaskan bahwa Bandung TV bisa menjadi "Jatidiri Pasundan" gitu,,,,"7

Kang Arya menjelaskan bahwa Bandung TV mengangkat "Jatidiri Pasundan" pada program-program budaya, seperti seni tari, program acara berbahasa sunda, program acara yang menceritakan sejarah sunda. Selain itu menurut Kang Arya program yang mengangkat kebudayaan Pasundan merupakan salah satu upaya branding “Jatidiri Pasundan”.

Untuk itu dalam program acaranyaBandung TV menentukan target yang dijelaskan oleh Kang Arya sebagai berikut:

“......kalau diklasifikasikan itu BCD kali ya, kalau Bandung TV sendiri itu target penontonnya itu BCD yang kelas-kelas menengah, kebawah juga, terus anakanak, karena itu,,, tayangan kita ya lebih memasyarakatlah intinya mah, terutama masyarakat Jawa Barat khususnya Bandung, mungkin globalnya ya Jawa Barat gitu,, kita semua, terutama dari segi tayangan kita mengangkat kebudayaan, selain kebudayaan kita punya segmen lainnya ada masuk disitu gitu,,,",

Kang Arya menjelaskan bahwa Bandung TV memiliki target yang dimulai dari kelas menengah, kebawah, serta anak-anak, selain itu program acara Bandung TV juga dibuat lebih

\footnotetext{
${ }^{7}$ Wawancara dengan Kang Arya pada Tanggal 23 Juni 2016

${ }^{8}$ Wawancara dengan Kang Arya pada Tanggal 23 Juni 2016
} 
memasyarakat. Daerah jangkauan Bandung TV adalah Jawa Barat khususnya Kota Bandung. Kang Arya juga menjelaskan bahwa Bandung TV memiliki stakeholder target:

“...Stakeholder target kita paling ke Spakeda-Spakeda dan dinas-dinas, terutama ya orang yang berkuasa di Bandung dan terutama Jawa Barat, misalnya Gubernur atau Walikota gitu,,, sama Bupati gitu,, kita mendekati itu tuh, karena mungkin dengan programprogramnya dari stakeholder sendiri mungkin bisa seimbang, menyeimbangkan dengan program kita yang ada....."

Kang Arya menjelaskan bahwa stakeholder yang menjadi target Bandung TV adalah Spakeda-Spakeda dan dinas-dinas serta orang-orang yang berkuasa di Bandung terutama Jawa Barat. Yang dimaksud dengan berkuasa menurut Kang Arya adalah Gubernur, Walikota, serta Bupati yang memiliki kekuasaan di wilayah Jawa Barat dan Bandung TV juga mendekati stakeholder untuk dapat bekerjasama dengan program yang dimiliki para stakeholder.

Dalam program acara Bandung TV yang berhubungan dengan stakeholder Kang Arya menjelaskan:

“....ketika stakeholder itu ada program tentang kebudayaan ya kita sama-sama karena kita juga mengangkat kebudayaan, kita bersama-sama dalam artian ketika si Walikotanya sendiri bikin program apa,,, Rebo Nyunda kita ada salah satu program Bandung TV ya Halo-Halo Bandung kita dengan segmen setiap hari rabu ya,

${ }^{9}$ Wawancara dengan Kang Arya pada Tanggal 23 Juni 2016 berbicara dengan bahasa Sunda si presenternya gitu...."10

Dalam program acara, Bandung TV juga melakukan kerja sama untuk mendukung program-program yang dimiliki oleh stakeholder. Menurut Kang Arya juga hal ini dilakukan untuk lebih meningkatkan partisipasi masyarakat terhadap Bandung TV serta ratingBandung $\mathrm{TV}$, terutama yang berkaitan dengan kebudayaan. Selain itu Kang Arya menjelaskan sebagai berikut:

“.....ya mungkin saya sampaikannya gini, ketika kita membuat program,, Bandung Tv membuat program untuk memberikan tayangan terutama tayangan kebudayaan, kebudayaan Sunda ya disini,, dengan berbagai konsep programnya itu sendiri ada program budaya dengan musik Sundanya,, dengan program budaya seni tradisinya,, dengan program budaya ada dialog mengundang para seniman dan budayawan untuk masuk kesitu berbicara tentang kebudayaan,,, ya mungkin dengan kita menontonkan hal-hal seperti itu,, para stakeholder mungkin bisa, intinya mah bahwa Bandung TV pun dalam hal ini,, dengan multisegmennya masih memegang teguh mottonya "Jatidiri Pasundan" gitu..."

Bandung TV dalam program acaranya lebih menitik beratkan kepada program acarakebudayaan. Selain itu program acara kebudayaan seperti program acara musikmusik sunda, program acara tradisi-tradisi sunda, program acaratalkshow dengan seniman serta budayawan sunda, dianggap dapat menyampaikan pesan "Jatidiri Pasundan” yang

\footnotetext{
${ }^{10}$ Wawancara dengan Kang Arya pada Tanggal 23 Juni 2016

${ }^{11}$ Wawancara dengan Kang Arya pada Tanggal 23 Juni 2016
} 
TANTANGAN ISI SIARAN DI ERA DIGITALISASI

menjadi brand Bandung TV karena kebudayaan merupakan ikon dari "Jatidiri Pasundan” yang dimiliki oleh Bandung TV.

Dalam program acara, Bandung TV juga menghadapi berbagai kendala, hal seperti yang di jelaskan oleh Kang Arya sebagai berikut:

"...hambatannya sih mungkin faktor schedule,.schedule tayangan kalau misalkan Kang Arya megang program live, ketika program live itu dipakai untuk,, ketika jam tayangan itu dipakai untuk program lain,, dalam artian ada marketing yang masuk,, otomatis program ini harus bisa mengalah, selama masih reguler disetiap harinya ada,, karena mungkin jam-jam itu mungkin bisa untuk di jual oleh marketing,, gitu aja sih,,"12

Kang Arya menjelaskan bahwa dalam program acara pun Bandung TV memiliki kendala dari mulai scheduleprogram acara yang selalu berubah-ubah sesuai dengan schedule marketing yang dapat menghasilkan uang. Kondisidikhawatirkan dapat mengurangi penonton yang menonton program acara karena jadwal yang berubah-ubah seketika menyulitkan penontonnya.

Kang Arya juga menjelaskan lebih lanjut tentang hambatan yang dimilikinya sebagai produser, sebagai berikut:

“.....hambatan yang Kang Arya pegangnya,,..Oh iya,, kalau programprogram tapping hambatannya mungkin dari segi schedule, schedule-lan dalam artian schedule hangkers, schedule kamera gitu,, kita harus benar-benar disusun schedule-nya karena kita terbatas dalam artian terbatas segi alatnya, jadi kita harus saling memberikan schedule dengan teman yang lain,, rekan yang lain ketika

\footnotetext{
${ }^{12}$ Wawancara dengan Kang Arya pada Tanggal 23 Juni 2016
}

berbarengan liputan kita harus,,, jangan sampai alat itu ditarik-tarik gitu,,, terutama kamera ya,,,,",13

Hambatan lain yang dihadapi Bandung TV sebagai televisi lokal adalah keterbatasan alat-alat untuk melakukan syuting program acara. dengan keterbatasan tersebut Bandung TV harus menyusun schedulepenggunaan alatalat agar tidak terjadi saling tarik-menarik untuk menggunakannya.

Keterlambatan pengisi acara menjadi hambatan yang sering dihadapi oleh Bandung TV dalam beberapaprogram acaranya. Kang Arya menjelaskan sebagai berikut:

“......Kalau misalkan karyawan terlambat itu sering, cuman kan kita antisipasinya ketika terlambat otomatis,, ketika program live ya,, selama program live itu bisa berjalan aman,,, berjalan gitu,, misalkan ada dua presenter, satu presenter datang terlambat, satu orang dulu bisa untuk bawain dulu opening seperti itu,,, kalau misalkan gak ada dua-duanya ya, mungkin fatal-fatalnya program itu di tayang ulangkan gitu,, giliran gitu kalau acara live ......"14

Hambatan lain yang berkaitan denganschedule, adalah keterbatasan jumlah crew Bandung TV terutama saat program live. Namun selama ini dapat diatasi dengan pengaturan kru agar program acara berjalan sesuai rencana, termasukapa bila adahost yang terlambat maka Kang Arya juga sudah memiki siasat untuk menanggulanginya, hal ini juga harus dilakukan oleh produser agar program acara berjalan sesuai rencana.

\footnotetext{
${ }^{13}$ Wawancara dengan Kang Arya pada Tanggal 23 Juni 2016

${ }^{14}$ Wawancara dengan Kang Arya pada Tanggal 23 Juni 2016
} 
ProTVF, Volume 1, Nomor, 1, Maret 2017, Hal. 31-46

Kemudian dalam program acara Bandung

TV juga memiliki respon dari konsumennya, yang dijelaskan Kang Arya sebagai berikut:

“.....kalau responnya selama ini sih,, ada yang komplen, ada yang bagus juga,, komplen dalam artian disini komplen negatif dan komplen positif ya,,, ada yang nerima oke, ada yang ya,,, wajar-wajar aja sih seperti itu sih. Maksudnya selam ini gak ada yang pernah sampai komplen fatal banget enggak,,, masih baik....."15

Respon konsumen atau penonton program acara menurut Kang Arya memiliki pro dan kontra, namun tetap ditanggapi positif oleh Bandung TV untuk membangun dan mengembangkan program acara agar lebih baik lagi. Selain itu tedapat indikator keberhasilan dari program acara Bandung TV yaitu sebagai berikut:

“.....cara mengukurnya sih menurut saya dengan AC Nielson ya,, tapi kita udah gak mengukur lagi itu,,, ya,,, dengan acara offair, off-air kita bisa melihat dari keberhasilan Bandung TV sendiri misalkan,, enggak selalu di on-air kan kita harus selalu,,, off-airnya seperti apa, antusias penonton yang hadir di acara offairnya gitu,,, banyak atau tidaknya,, dilihat dari situ juga,,",16

AC Nielson merupakan salah satu lembaga yang melakukan rating terhadap media-media TV di Indonesia. Bandung TV dalam program acaranya menggunakan antusias serta banyaknya jumlah penonton yang hadir untuk menentukan keberhasilannya serta dari telepon yang masuk dalam acara onair dan dari media sosial serta share penonton

\footnotetext{
${ }^{15}$ Wawancara dengan Kang Arya pada Tanggal 23 Juni 2016

${ }^{16}$ Wawancara dengan Kang Arya pada Tanggal 23 Juni 2016
}

dalam program acara ketika program acara berlangsung.

Bandung TV menggunakan lembaga AC Neilson sebagai dukungan untuk melakukan penghitungan kuantitatif dan melihat perkembangan dari program acara Bandung TV dan melihat perkembangan nilai subtansial dari brand "Jatidiri Pasundan" yang dimiliki Bandung TV. Hal ini sesuai dengan yang dijelaskan Aaker (2015:5) bahwa dukungan kuantitatif untuk brand sebagai aset didasari oleh data hasil riset yang menunjukan bahwa brand memang memiliki nilai aset yang subtantial.

Selain itu Bandung TV juga menentukan aturan tertentu kepada host agar dapat sesuai dengan "Jatidiri Pasundan" hal ini dijelaskan Kang Arya sebagai berikut:

“......kostum ketika di program anu misalkan,, misalkan presenter anu pas di program Bentang Parahyangan harus kostumnya seperti ini,, iya kita harus tentukan seperti itu,, ketika kita masuk di Halo-Halo Bandung kostumnya seperti ini,, ketika masik si Jagad Parahyangan kostum presenter harus seperti ini,,, kita yang tentukan juga, karena apa,,, karena mungkin nanti di situ, kalau misalkan Jagad Parahyangan kan kita dibikin sketsa dulu sedikit,, dalam artian ya,,, ada tema yang bisa masuk dalam tema kostum dan tema dalam si,, di pas hari itu live,, ada temanya,, kostumnya pun harus ikut,,, maksudnya harus sama dengan tema di program itu......"17

Penentuan kostum dilakukan agar pesan dari program serta pesan dari brand "Jatidiri Pasundan" dapar tersampaikan dengan baik.

\footnotetext{
${ }^{17}$ Wawancara dengan Kang Arya pada Tanggal 23 Juni 2016
} 
Bandung TV juga menentukan kostum agar sesuai dengan tema acara yang lebih mendominasi kebudayaan sunda. Kemudian Kang Arya menjelaskan sebagai berikut:

"Bandung TV dengan komitmen... Insyaalloh,, dengan komitmen "Jatidiri Pasundan", kita masih dengan komitmen itu,, kita tetap masih di dalam jalur itu, ......", 18

Meskipun dengan keterbatasan yang dimilikinya dari mulai alat-alat hingga sumber dayanya, Bandung TV selama 11 tahun masih tetap mempertahankan brand "Jatidiri Pasundan" yang dimilikinya karena merupakan ikon sera identitas dari Bandung TV sebagai TV lokal Jawa Barat pertama.

Brand (merek) menurut Aaker (2015:15) menyatakan bahwa brand lebih dari sekedar nama dan logo, brandmerupakan janji satu organisasi kepada pelanggan untuk memberikan apa yang menjadi prinsip brand itu, tidak hanya dalam hal manfaat fungsional, tetapi juga manfaat emosional, ekspresi diri, dan sosial. Sedangkan branding menurut Aaker (2015:229)diartikan sebagai merepresentasikan brand.Pelaksanaan branding "Jatidiri Pasundan" sebenarnya sudah dilakukan Bandung TV sejak 11 tahun yang lalu tepatnya ketika usianya yang ke 1 tahun, Bandung TV menetapkanbrand "Jatidiri Pasundan". Bandung TV memulai branding "Jatidiri Pasundan" dengan memposisikan Bandung TV sebagai wadah kreativitas masyarakat Pasundan (Sunda).

${ }^{18}$ Wawancara dengan Kang Arya pada Tanggal 23 Juni 2016
Slogan Jatidiri Pasundan ditujukan untuk mengangkat kembali nilai-nilai budaya dan potensi lokal yang terdapat di Jawa Barat. Selama 11 tahun perjalanannya Bandung TV telah menciptakan program-program program acara yang mencerminkan "Jatidiri Pasundan" sebagai dasar dari tema-tema program acaranya. Dalam pembuatan setiapprogram acaraditurunkan faktor-faktor atau nilai-nilai yang terkandung dalam "Jatidiri Pasundan" seperti sikap hidup, lingkungan hidup, kebudayaan dan lain sebagainya.Jatidiri adalah suatu identitas yang menggambarkan sekelompok orang atau suku bangsa. Jatidiri digambarkan sebagai karakter atau sifat yang berhubungan dengan budaya, dalam hal ini jatidiri Pasundan merupakan karakter atau sifat masyarakat Pasundan atau suku Sunda yang tekenal dengan keramahannya, sopan santunya serta sikap optimis dan periang.

Hakim (dalam Azmil, 2012) mengutip ada lima hal yang termasuk dalam jatidiri suku Sunda (Pasundan), yaitu cageur, bageur, bener, singer dan pinter (sehat, sopansantun, taat aturan, cekatan dan cerdas). Cageur adalah sehat jasmani maupun rohani direalisasikan dalam tindakan menjaga kesehatan dan hidup yang sehat. Bageur adalah perilaku sopan santud dan ramah tamah terhadap siapa saja, tua-muda, kaya-miskin, berpangkat ataupun tidak. Adapun bener adalah sikap teguh memegang aturan, baik aturan sosial amupun aturan agama. Singer secara umum menggambarkan perilaku cekatan, trampil dan mawas diri, sedangkan pinter adalah 
kecerdasan. Cerdas dalam arti yang luas, tidak hanya kecerdasan intelektual namun mencakup wawasan yang luas. ${ }^{19}$

Setelah menentukan nilai-nilai yang terkandung dalam "Jatidiri Pasundan" kemudian Bandung TV menciptakan sebuah program-program yang berhubungan dengan nilai-nilai tersebut. Selama 11 tahun Bandung TV selau memasukan konsep "Jatidiri Pasundan" dalam program acaranya.Dimulai dengan penentuan tema program acara, kemudian background panggung, konstum dari host dan bintang tamu, selanjutnya bahasa yang digunakan dalam program acara Bandung TV juga menggunakan bahasa tradisional Jawa Barat yaitu bahasa sunda. Kemudian Bandung TV juga menampilkan informasi-informasi yang berhubungan dengan Jawa Barat dari mulai kesenian, adat-istiadat, berita-berita seputar Jawa Barat khususnya Kota Bandung, lagu-lagu yang berasal dari Jawa Barat yang berupa tembang sunda cianjuran, kawih,dan lagu - lagu pop sunda.

Pelaksanaan branding "Jatidiri Pasundan" Bandung TV dapat terlihat dari salah satu program acara yang sudah ada di Bandung TV sejak dari didirikannya Bandung TV yaitu Bentang Parahyangan. Program cara Bentang Parahyangan merupakan acara unggulan Bandung TV yang sudah bertahan hingga 11 tahun. program acara Bentang Parahyangan merupakan salah satu contoh dari pelaksanaan branding "Jatidiri Pasundan".Dimulai dengan

\footnotetext{
${ }^{19}$ http://catatanazmil.blogspot.co.id/2012/01/jati-dirisunda.html
}

tema acara dari Bentang Parahyangan yang merupakan program acara yang menampilkan artis-artis lokal Jawa Barat, selain itu acara Bentang Parahyangan juga menampilkan musik-musik sunda yang merupakan kebudayaan khas Jawa Barat, kemudian memperkenalkan juga kesenian-kesenian tradisional Jawa Barat dalam bentuk musik dan tari. Selanjutnya "Jatidiri Pasundan" dalam program acara Bentang Parahyangan tercermin juga dari dekorasi danbackground panggung yang bernuansa sunda dengan ukiran-ukiran khas Jawa Barat.Nama acara Bentang Parahyangan yang berasal dari bahasa sunda yang berarti bintang-bintang dari tanah parahiyangan(tanah Pasundan atau Jawa Barat).

Selain itu juga Bandung TV selalu menggunakan nama-nama yang diambil dari bahasa sunda serta cerita hidup rakyat Jawa Barat untuk nama program acaranya seperti Mandalawangi yang merupakan program acara yang menyajikan berbagai informasi objek pariwisata dan tempat-tempat menarik untuk berwisata di sekitar daerah Bandung, Bajigur Bandung yang merupakan program acara yang menyajikan profil rakyat kecil yang terus berjuang dan bekerja secara tekun dalam mengerjakan pekerjaannya yang halal untuk bertahan hidup di Bandung dan sekitarnya.Klip Parahyangan juga merupakan salah satu program acara musik yang menayangkan klipklip musik berbahasa Sunda yang dibawakan oleh para artis Bandung, selanjutnya ada Jagad Parahyangan yang merupakan program acara talkshow namun dari host hingga bintang tamu 
TANTANGAN ISI SIARAN DI ERA DIGITALISASI

semuanya menggunakan bahasa sunda. Branding "Jatidiri Pasundan" direalisasikan dalam keramahan para pembawa acara, kostum-kostum para hostnya dalam pakaian tradisional Jawa Barat yang merupaka ciri khas budaya Sunda/Pasundan, seperti baju kebaya, pangsi dan sebagainya.

Dalam pelaksanaannya Bandung TV selalu memasukan unsur-unsur "Jatidiri Pasundan" dalam program acaranya baik secara langsung maupun secara tidak langsung. Contoh lain adalah Bandung TV memiliki program acara berita khusus berbahasa sunda yaitu Kalawarta, program ini adalah pemberian informasi berita seputar tanah air khususnyaJawa Barat dengan menggunakan bahasa Sunda. Bandung TV juga memiliki program acara anak-anak yang merupakan kesenian Sunda dan permainan tradisional sunda yang sudah jarang dilakukan oleh anak-anak masa sekarang. Acara ini bertujuan agar generasi muda Pasundan lebih mengenal budayanya dari hal yang paling sederhana. Budaya dan adat istiadat juga termasuk “Jatidiri Pasundan”.Penggunaan Bahasa Sunda dalam program acara Bandung TV selalu menjadi pilihan utama untuk para hostnya, kemudian pemilihan soundtrack latar belakang lagu dari tiap-tiap program acara Bandung TV juga mengandung unsur-unsur tradisional.

Menurut Rhenald Khasali (2013:44) pada Camera Brandingyang baik pada dasarnya hanya dapat dibangun diatas 2 fondasi kuat, yaitu Cameragenic dan Auragenic. Cameragenic menyangkut Attractiveness subjek di hadapan kamera, sebuah kesan yang ditangkap dari tampilan fisik, sedangkan Auragenic menimbulkan aura kekuatan perubahan, keindahan, atau kesenangan bagi pemirsa televisi. Sederhananya Auragenic adalah sebuah rasa yang ditangkap dari interaksi.

Bandung TV berusaha memunculkan Cameragenic dalam program acaranya dengan cara menampilkan tokoh atau pembicara yang memiliki image budayawan Sunda, hal ini dilakukan karena dengan menampilkan tokoh atau pembicara yang memiliki pengetahuan lebih tentang budaya Sunda maka akan menciptakan kesan bahwa Bandung TV merupakan televisi yang memiliki brand "Jatidiri Pasundan". Bandung TV juga menampilkan para artis dan seniman lokal dalam beberapa program program acara, hal ini juga dilakukan Bandung untuk menciptakan kesan bahwa Bandung TV sebagai "Jatidiri Pasundan" peduli dan ikut melestarikan musikmusik lokal yang berbahasa Sunda serta mendukung seniman-seniman lokal Jawa Barat untuk berkarya.

Bandung TV juga berusaha menciptakan Auragenic dalam program acaranya dengan menciptakan tema-tema yang menimbulkan rasa senang dan bangga serta cinta terhadap budaya Sunda, seperti musik-musik lokal (Sunda) yang di senangi oleh pemirsanya, tema-tema yang dibicarakan dalam beberapa acara juga merupakan tema budaya Sunda yang disenangi dan sedang banyak dibicarakan oleh pemirsanya. Bandung TV menciptakan aura 
keindahan dalam program acaranya dengan memberikan tema budaya Sunda pada kostum yang dikenakan para host seperti kebaya yang terkenal dengan keindahan gaunnya dan merupakan pakaian khas Jawa Barat. Bandung TV menampilkan keindahan hasil-hasil seniman lokal untuk diperlihatkan kepada publik contohnya ukiran, wayang golek,seni tari tradisional maupun modern. Bandung TV juga berusaha menampilkan aura kekuatan Jatidiri Pasundan dalamprogram acaranya yaitu dengan menggunakan bahasa Sunda dan nilainilai budaya dalam acaranya, kekuatan yang ingin di tampilkan adalah rasa bangga terhadap budaya dan bahasa Sunda.

Berbagai upaya yang dilakukan Bandung TV diharapkan akan menjadi filter untuk menyaring segala informasi dalam arus globalisasi, oleh karena itu dalam beberapa program acaranya Bandung TV selalu menampilkan unsur-unsur budaya dari tokoh, musik, bahasa, hingga nilai-nilai budaya karena hal tersebut juga termasuk dalam branding "Jatidiri Pasundan".

\section{SIMPULAN}

Pengelola Bandung TV melaksanakan branding "Jatidiri Pasundan" melalui tayangan televisi dengan memilih dan membuat konsep tayangan yang mengandung nilai-nilai budaya Sunda/Pasundan.Misalnya penggunaan bahasa Sunda pada tayangan Bandung TV untuk meningkatkan kebanggaan terhadap bahasa daerah, tema kostum yang digunakan para host dalam tayangan Bandung TV adalah pakaian daerah untuk meningkatkan kecintaan terhadap karya budaya lokal, penayangan tayangan seni dan budaya dalam tayangan Bandung TV, penayangan klip-klip atau musik-musik lokal berbahasa sunda, penayangan karya seni lokal seperti tarian-tarian daerah Jawa Barat,pertujukan wayang, mengundang bintang tamu yang memiliki kontribusi tinggi terhadap Jawa Barat, baik artis, tokoh-tokoh penting, budayawan, seniman dan lain-lain.

\section{DAFTAR PUSTAKA}

Aaker, David. 2015. Aaker On Branding. Jakarta: PT Gramedia Pustaka Utama.

Ardianto, Elvinaro dkk. 2007. Komunikasi Massa. Bandung: Simbiosa Rekatama Media.

.2009. Public Relations Praktis. Bandung: Widjaya Padjajaran. .2010. Metode Penelitian untuk Public Relations Kuantitatif dan Kualitatif. Bandung: Simbiosa Rekatama Media

2011. Handbook Of Public Relations. Bandung: Simbiosa Rekatama Media.

Arikunto S, 2006. Prosedur Penelitian Suatu Pendekatan Praktik, Ed Revisi VI, Penerbit PT Rineka Cipta, Jakarta.

Bungin, Burhan. 2015. Konstruksi Sosial Media Massa. Jakarta: Prenada Media Group.

Creswell, John W. 2014. Research Design Pendekatan Kualitatif, Kuantitatif da Mixed. Diterjemahkan oleh Achmad Fawaid. Yogyakarta:Pustaka Pelajar.

Freeman, R. E. 1984. Strategic Management: A Stakeholder Approach, Boston, Pitman.

Herdiansyah, Haris. 2010. Metodologi Penelitian Kualitatif Untuk Ilmu-Ilmu Sosial. Jakarta: Salemba Humanika

Kasali, Rhenald. 2013. Camera Branding Cameragenic vs. Auragenic. Jakarta: PT Gramedia

Moleong, Lexy,. 2006. Metodologi Penelitian Kualitatif. Bandung: PT. Remaja Rosdakarya 
TANTANGAN ISI SIARAN DI ERA DIGITALISASI

Morissan. 2004. Jurnalistik Televisi Mutakhir. Bogor: Ghalia Indonesia

Pudjiastuti, Wahyuni. 2010. Special Event : Alternatif Jitu Membidik Pasar. Jakarta: PT Elex Media Komputindo.

Rakhmat, Jalaluddin. 1989. Metode Penelitian Komunikasi. Bandung: CV Remaja Karya.

Salim,Agus.2006.Teori Dan Paradigma Penelitian Sosial.Yogyakarta:Tiara Wacana

Singarimbun, Masri. 1987. Metode Penelitian Survai. Jakarta: LP3ES

Sugiyono. 2005. Metode Penelitian Kualitatif. Bandung: Alfabeta . 2008. Metode Penelitian Kuantitatif Kualitatif dan R\&D. Bandung Alfabeta. . 2011. Metode Penelitian Kuantitatif Kualitatif dan R\&D. Bandung Alfabeta.
Sukidin, Basrowi. 2002. Metode Penelitian Kualitatif Perspektif Mikro. Surabaya: Insan Cendekia.

Sumadiria, AS Haris. 2011. Jurnalistik Indonesia (Menulis Berita dan Feature). Bandung : Simbiosa Rekatama Media.

Syahputra, Iswandi. 2006. Jurnalistik Infotainment. Yogyakarta: Pilar Media.

Wasesa, Agung. 2011. Political Branding \& Public Relations. Jakarta: PT Gramedia Pustaka Utama.

\section{Sumber Lain-Lain:}

www.bandungtv.co.id

http://catatanazmil.blogspot.co.id/2012/01/jati-

diri-sunda.html 